\title{
Spontaneous nasal septal haematoma and abscess: a case report and literature review*
}

\author{
Craig P. Mooney ${ }^{1,2}$, Joanne Rimmer 1,3 \\ 'Department of Otolaryngology Head \& Neck Surgery, Monash Health, Melbourne, Australia \\ 2 Sydney Medical School, University of Sydney, Sydney, Australia \\ ${ }^{3}$ Department of Surgery, Monash University, Melbourne, Australia
}

Rhinology Online, Vol 1: 122 - 126, 2018

http://doi.org/10.4193/RHINOL/18.075

*Received for publication:

September 11, 2018

Accepted: September 17, 2018

Published: September 29, 2018

\begin{abstract}
Background: Spontaneous nasal septal haematoma or abscess is a rare condition that can result in serious infective and cosmetic complications.
\end{abstract}

Methodology: We present a case of a delayed diagnosis of a spontaneous nasal septal haematoma in a healthy 53-year old male, as well as a comprehensive review of the literature on spontaneous nasal septal haematoma and abscess.

Results: Spontaneous nasal haematoma and abscess are rare entities with only 2 previous reports of spontaneous nasal septal abscess in immunocompetent adults and one paper reporting spontaneous nasal septal haematoma in a Nigerian population.

Conclusions: Nasal septal haematoma can occur spontaneously in healthy individuals with no predisposing factors or trauma. Prompt recognition and treatment is paramount to avoid potentially serious complications.

Key words: nasal septum, nose, nose deformities, acquired

\section{Introduction}

Nasal septal haematoma (NSH) is most frequently encountered as an uncommon complication of nasal trauma or surgery that can be complicated by superimposed abscess formation if left untreated $^{(1,2)}$. We present a case of a spontaneous NSH in a healthy 53-year-old man presenting with a nine-day history of septal swelling and nasal obstruction. We review the literature on NSH and nasal septal abscess (NSA), including reported spontaneous cases, rare causes, complications and principles of management.

\section{Case report}

A previously well and active 53-year-old man presented to the emergency department of a major urban teaching hospital with a nine-day history of sudden onset nasal obstruction, pain and swelling. The patient denied any minor or major facial trauma in the weeks prior to developing his symptoms, nor any history of sinusitis, septal furuncle, dental pain or symptoms suggestive of a dental infection. The nasal obstruction was initially accompanied by low grade fevers that resolved within the first 48-72 hours, moderate pain that had resolved prior to presentation, nasal dorsal swelling and clear rhinorrhoea. The patient denied any history of prolonged bleeding, easy bruising, recurrent infections, immunosuppression or a family history of the same. He had presented to his primary care physician within 72 hours of symptom onset and was prescribed a course of oral amoxicillin and clavulanic acid with minimal improvement.

On examination the patient was afebrile with marked tenderness and swelling of the nasal dorsum. There was mild erythema of the columella but no features of facial cellulitis. There was almost complete obstruction of the nasal vestibules bilaterally due to significant anterior nasal septal swelling that was cherry red, fluctuant and tender to palpation (Figure 1). Full blood count was significant for a leukocystosis of $15 \times 10^{9} / \mathrm{L}$ (normal range $\left.4.0-11.0 \times 10^{9} / \mathrm{L}\right)$, predominately due to a neutrophilia of $9.3 \times 10^{9} / \mathrm{L}$ (normal range $2.0-8.0 \times 10^{9} / \mathrm{L}$ ) and a monocytosis of $1.95 \times 10^{9} / \mathrm{L}$ (normal range $0.2-1.00 \times 10^{9} / \mathrm{L}$ ).

A diagnosis of seemingly spontaneous NSH/NSA was suspected, and the patient was placed on intravenous cephazolin and 


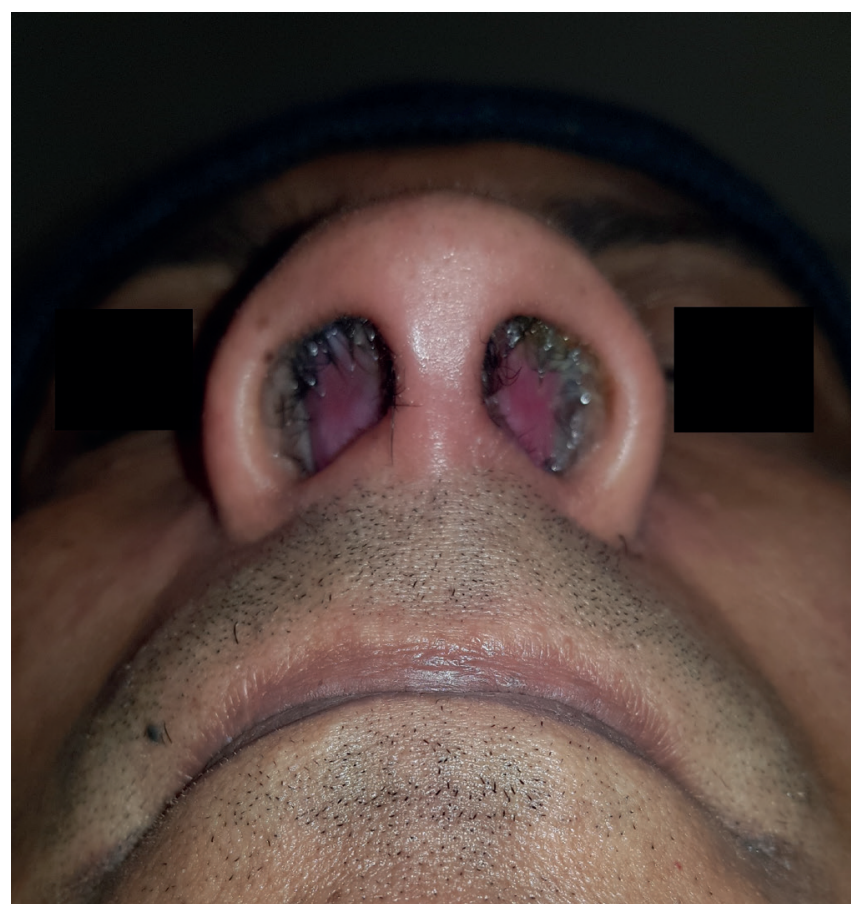

Figure 1. Anterior bilateral nasal septal swelling causing bilateral nasal obstruction.

consented for an incision and drainage that occurred within 24 hours of presentation. At surgery, a hemitransfixion incision was made; purulent material was evacuated from the submucoperichondrial plane and sent for culture and sensitivities. Examination of the septal cartilage remarkably revealed a predominately intact quadrilateral cartilage with only a small defect suproanteriorly and adjacent necrotic perichondrium that was debrided. A small drain was inserted and the mucoperichondrial flap closed with a transseptal quilting suture. Intravenous cephazolin was continued.

A mildly elevated INR of 1.3 (normal range $0.8-1.2$ ) on admission had normalised by day 1 of the admission without intervention; specialist haematology opinion advised against further investigation. Culture of the purulent exudate grew Staphylococcus aureus resistant to penicillin but sensitive to cephalexin, clindamycin, erythromycin and flucloxacillin. The patient was discharged after removal of the drain 48 hours postoperatively and continued oral cephalexin. He remained systemically well and afebrile for the duration of his admission with normalisation of his leukocystosis prior to discharge.

At one week the patient remained well with moderate improvement in nasal obstruction but with residual septal swelling. At eight weeks the septal swelling had completely resolved with return to normal nasal function. A mild saddle deformity had developed which the patient had noted but at this stage was unconcerned with the change in cosmesis (Figure 2).

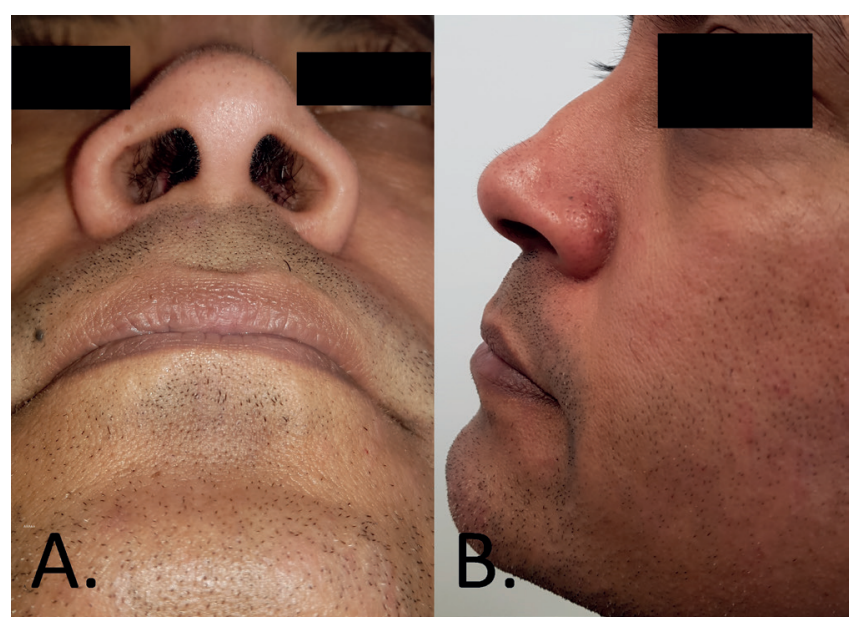

Figure 2. Appearance of nose at 8 weeks post incision and drainage. A. complete resolution of septal swelling and obstruction. B. Resultant dorsal nasal saddle deformity.

\section{Literature review}

A comprehensive review of the literature was performed in MEDLINE using the search terms (nasal sept*) and ( $\mathrm{h}^{*}$ ematoma or abscess*) as subject headings and keywords with no restriction on date but limited to English language. References from relevant articles were reviewed to identify any further articles.

Spontaneous NSH or NSA in adults and in the absence of immunosuppression or coagulopathy is extremely rare with only two previously reported cases of spontaneous NSA in the literature and one paper describing a series of spontaneous NSH in a Nigerian population ${ }^{(3)}$. NSA in the immuncompromised has been reported secondary to a variety of underlying causes including insulin and non-insulin dependent diabetes ${ }^{(4)}, \mathrm{HIV}^{(5)}$, haematological malignancies and chemotherapy ${ }^{(6)}$.

Bennett and Rapado reported a case of a 39 year old female with a three week history of nasal congestion and anterior septal nasal swelling wth no precipitating event or underlying pathology ${ }^{(7)}$. Incision and drainage of the collection revealed a NSA with loss of the central quadrilateral cartilage but preservation of caudal and dorsal struts. No follow up was reported.

Salam and Camilleri described the case of a 38 year old female with a 4 day history of a painful, swollen, congested and erythematous nose that did not improve with oral antibiotics ${ }^{(8)}$. The patient reported no history of trauma, sinusitis or dental infection. The patient was mildly febrile and anterior rhinoscopy revealed the typical swollen and tender anterior septum. The patient was commenced on intravenous amoxicillin/clavulanic acid. Incision and drainage under general anaesthesia revealed an intact septal cartilage and an abscess cavity that was evacuated. No cosmetic deformity was present at 2 weeks but longer follow up 
Table 1. Reported cases of paediatric spontaneous NSA.

\begin{tabular}{|c|c|c|c|c|}
\hline Age & Gender & $\begin{array}{l}\text { Duration of } \\
\text { symptoms (days) }\end{array}$ & Antibiotic treatment & Comment \\
\hline 4 months ${ }^{(32)}$ & Female & 14 & Cotrimoxazole & $\begin{array}{l}\text { Complicated by intracerebral abscess and skull base } \\
\text { osteomyelitis }\end{array}$ \\
\hline 21 months ${ }^{(33)}$ & Male & 14 & Not reported & Auto-discharged \\
\hline 7 years ${ }^{(34)}$ & Male & 5 & $\begin{array}{l}\text { Vancomycin and piperacillin/ } \\
\text { tazobactam }\end{array}$ & \\
\hline 11 years $^{(35)}$ & Female & 2 & Ampicillin/Sulbactam & \\
\hline 11 years $^{(33)}$ & Male & 3 & Not reported & $\begin{array}{l}\text { History of recurrent infections but no reported im- } \\
\text { munodeficiency investigation }\end{array}$ \\
\hline
\end{tabular}

Table 2. Rare causes of NSH and NSA.

Sphenoid ostia balloon dilatation ${ }^{(36)}$
Ethmoid sinusitis $^{(37)}$
Frontal Sinusitis $^{(16)}$
Medication related osteonecrosis of the jaw ${ }^{(38)}$
Nasotracheal intubation ${ }^{(39)}$
Dentigerous cyst ${ }^{(40)}$
Dental carries ${ }^{(41)}$
Nasal insufflation

Table 3. Reported complications of NSA.

Naso-oral fistula $^{(43)}$
Meningitis $^{(44)}$
Subdural abscess $^{(31)}$
Septic arthritis
Sigm
Skull base osteomyelitis ${ }^{(32)}$

was not reported.

Chukuezi et al. reported a consecutive series of 46 patients with $\mathrm{NSH}$ in a Nigerian general hospital ${ }^{(3)}$. The age range was from 2 to 60 years and the aetiology of the haematoma was attributed to either trauma, in 14 cases, or spontaneous, 32 cases. No other potential contributing factors were reported, including bleeding diathesis, immunosuppression, previous surgery or recent infection. Eight of the spontaneous cases were reported in the discussion as users of intranasal tobacco snuff, but these cases were not re-assigned from the spontaneous group. Eight of the patients were found to have developed NSA at the time of incision and drainge with four having intracranial complications. The reported relative incidence of spontaneous to non-spontaneous NSH in this paper makes it an outlier within the literature. This raises the possibility that other contributing or local causative factors, such as tobacco snuff use, have not been assessed or reported in this paper with the effect of artificially raising the percentage of cases reported as spontaneous.

A higher number of spontaneous NSH and NSA are reported in the paediatric population (Table 1). This increased frequency could be due a variety of factors that make identifying a precipitating event more difficult, rather than any true increased predisposition to spontaneous NSH or NSA. These include difficulties in self reporting of injuries as well as anatomical differences that make minor trauma more likely to result in NSH. For the same reasons NSA is more likely to develop due to delay in recognition and diagnosis of NSH.

\section{Discussion}

NSH or NSA are defined as a collection of blood or pus respectively between the nasal septum and mucoperichondrium or periosteum ${ }^{(9)}$. The first reported case of a NSH in the literature was in 1810 by Cloquet who also described the treatment principle of incision and drainage ${ }^{(10)}$. NSH is most commonly seen as a complication of facial or nasal trauma ${ }^{(11)}$ or as a post-operative complication following septal surgery ${ }^{(12)}$. NSA is thought to most frequently occur due to superimposed bacterial colonisation of a haematoma ${ }^{(12)}$ or as a complication of septal surgery ${ }^{(13)}$. Other reported causes include nasal furuncle(1) and infection from adjacent structures. Rare causes for NSA and NSH have also been reported in the literature (Table 2).

NSH presents with relatively sudden onset of bilateral nasal obstruction, septal and nasal dorsal swelling, pain, and fevers in the initial 48-72 hours ${ }^{(9)}$. NSA presents similarly but with a tendency to a longer duration of symptoms and delay in presentation ${ }^{(2,14)}$, persistent fevers, facial erythema or cellulitis and increased swelling and tenderness ${ }^{(15)}$. Clinical examination, particularly anterior rhinoscopy, will confirm the diagnosis with the presence of a swollen, erythematous and boggy nasal septum with at least partial if not complete obstruction of the anterior nasal airways. The less frequently reported posterior NSA may present without the typically anterior nasal swelling and may require rigid nasendoscopy to confirm the diagnosis and 
identify any causative factors ${ }^{(16)}$. Reported cases of late onset of NSH after trauma with a normal examination on presentation have been reported and illustrate the importance of appropriate patient counselling and clinician vigilance ${ }^{(17)}$.

$\mathrm{NSH}$ is more prevalent in the paediatric population due to differences in structure and anatomy of the immature nasal septum $^{(18,19)}$. A softer and more flexible septal cartilage combined with a loosely adherent mucoperichondrium are thought to make NSH more common, particularly after minor trauma ${ }^{(9)}$. Rates of subsequent NSA formation are also thought to be higher due to delay in recognition from minor injuries with often no external signs of injury and the difficulty often encountered in performing adequate examination in this population ${ }^{(20,21)}$. Consideration of non-accidental injury in children with NSA or $\mathrm{NSH}$, particularly under the age of 2 , has been suggested by several authors ${ }^{(9,22)}$.

The mainstay of NSA and NSH treatment is incision and drainage ${ }^{(23)}$ and intravenous or oral antibiotic therapy ${ }^{(9,15,24)}$. The most common organisms isolated from NSH include Streptococcus species, Haemophilus influenza and Staphylococcus aureus ${ }^{(9,}$ 23). Cases of methicillin resistant Staphylococcus aureus (MRSA) $\mathrm{NSA}^{(25)}$ and fungal NSA have also been described in immunocompromised patients ${ }^{(26)}$ illustrating the importance of maintaining a high index of suspicion for uncommon causative microbes in high risk patient groups including those not responding to appropriate treatment or in recurrent abscesses ${ }^{(16)}$.

Nasal packing ${ }^{(11)}$ and/or septal quilting sutures ${ }^{(27)}$ are used to reduce the potential of re-accumulation of blood or pus but the possibility of recurrent NSH or subsequent NSA should always be considered ${ }^{(2)}$. If marked destruction of the septal cartilage is identified at the time of surgery and cosmetic deformity is likely to result, a decision to perform early or delayed reconstruction can be made. Satisfactory long-term results of immediate septal reconstruction have been reported in the literature ${ }^{(28,29)}$.

Untreated NSA or NSH can result in nasal deformity due to destruction of the nasal septal cartilage from pressure necrosis or disruption of the blood supply from the overlying mucoperichondrium, and in the setting of NSA, direct effects of the infec- tive organism ${ }^{(30)}$. NSA can result in a variety of rare complications including potentially life-threatening intracranial complications due to the rich lymphatic and valveless venous complex of the nasal septum ${ }^{(9)}$ (Table 3). At least one author has advocated for the judicious use of computed tomographic imaging with any suggestion of complication ${ }^{(31)}$.

Despite purulent material being drained at the time of surgery, we believe this case represents a spontaneous NSH that subsequently developed into an abscess. We favour this diagnosis over a primary spontaneous NSA due to the long delay between initially developing symptoms and presentation as well as the absence of persistent fevers, facial cellulitis, systemic toxaemia or other complication even in the context of treatment with oral antibiotics from the primary care physician. Delay in referral to a tertiary referral centre for otolaryngological opinion resulted in external nasal deformity even with minimal cartilaginous destruction identified at the time of incision and drainage.

\section{Conclusion}

NSH and NSA are rare clinical entities. NSH can occur in healthy individuals with no predisposing factors or history of trauma. Delay in presentation or diagnosis can result in serious life threatening infective sequalae as well as long term cosmetic and functional problems. Prompt recognition by medical professionals and early treatment is required to avoid long term and serious complications.

\section{Consent to publish}

Written informed consent for publication of the patient's clinical details and images was obtained from the patient. A copy of the consent form is available for review by the Editor of this journal.

\section{Authorship contribution}

CM conducted the literature review, acquired the case history and completed initial drafting of the manuscript. JR proposed the concept and structure of the manuscript and critically revised the manuscript. All authors read and approved the final manuscript.

\section{Conflict of interest}

The authors have no conflicts of interest to declare.

\section{References}

1. Ambrus PS, Eavey RD, Baker AS, Wilson WR, Kelly JH. Management of nasal septal abscess. Laryngoscope. 1981 Apr;91(4):57582.

2. Kryger H, Dommerby H. Haematoma and abscess of the nasal septum. Clin Otolaryngol Allied Sci. 1987 Apr;12(2):125-9.

3. Chukuezi AB. Nasal septal haematoma in Nigeria. J Laryngol Otol. 1992
May;106(5):396-8

4. Dinesh R, Avatar S, Haron A, Suhana, Azwarizan. Nasal septal abscess with uncontrolled diabetes mellitus: case reports. Med J Malaysia. 2011 Aug;66(3):253-4.

5. Sandel HDt, Davison SP. Three spontaneous occurrences of nasal septal abscess in patients with chronic asymptomatic HIV-the need for early intervention and reconstruction. Ear Nose Throat J. 2009 Aug;88(8):1058-66.

6. Debnam JM, Gillenwater AM, Ginsberg LE. Nasal septal abscess in patients with immunosuppression. AJNR Am J Neuroradiol. 2007 Nov-Dec;28(10):1878-9.

7. Bennett JD, Rapado F. Nasal septal abscess in a healthy, non-immunocompromised patient. Hosp Med. 1998 Jan;59(1):78.

8. Salam B, Camilleri A. Non-traumatic nasal 
septal abscess in an immunocompetent patient. Rhinology. 2009 Dec;47(4):476-7.

9. Canty PA, Berkowitz RG. Hematoma and abscess of the nasal septum in children. Arch Otolaryngol Head Neck Surg. 1996 Dec;122(12):1373-6.

10. Pirsig W. Historical notes and actual observations on the nasal septal abscess especially in children. Int J Pediatr Otorhinolaryngol. 1984 Oct;8(1):43-54

11. Olsen KD, Carpenter RJ, 3rd, Kern EB. Nasal septal injury in children. Diagnosis and management. Arch Otolaryngol. 1980 Jun;106(6):317-20.

12. Shapiro RS. Nasal septal abscess. Can Med Assoc J. 1978 Dec;119(11):1321-3.

13. Makitie A, Aaltonen LM, Hytonen M Malmberg $\mathrm{H}$. Postoperative infection following nasal septoplasty. Acta Otolaryngol Suppl. 2000 Jul;543:165-6.

14. Sayin I, Yazici ZM, Bozkurt E, Kayhan FT. Nasal septal hematoma and abscess in children. J Craniofac Surg. 2011 Nov;22(6):e17-9.

15. Ginsburg CM, Leach JL. Infected nasal septal hematoma. Pediatr Infect Dis J. 1995 Nov;14(11):1012-3.

16. Waterhouse D, Hornibrook J. A rare cause of nasal septal abscess. N Z Med J. 2013 Apr;126(1372):89-91.

17. Dubach P, Aebi C, Caversaccio M. Lateonset posttraumatic septal hematoma and abscess formation in a six-year-old Tami girl--case report and literature review. Rhinology. 2008 Dec;46(4):342-4.

18. Johnson MD. Management of Pediatric Nasal Surgery (Rhinoplasty). Facial Plast Surg Clin North Am. 2017 May;25(2):211-21.

19. Wright RJ, Murakami CS, Ambro BT Pediatric nasal injuries and management. Facial Plast Surg. 2011 Oct;27(5):483-90.

20. East CA, O'Donaghue G. Acute nasa trauma in children. J Pediatr Surg. 1987 Apr;22(4):308-10.

21. Alvarez H, Osorio J, De Diego Jl, Prim MP, De La Torre C, Gavilan J. Sequelae after nasa septum injuries in children. Auris Nasus Larynx. 2000 Oct;27(4):339-42.

22. Toback S. Nasal septal hematoma in an 11-month-old infant: a case report and review of the literature. Pediatr Emerg Care. 2003 Aug:19(4):265-7.

23. Dispenza C, Saraniti C, Dispenza F,
Caramanna C, Salzano FA. Management of nasal septal abscess in childhood: our experience. Int J Pediatr Otorhinolaryngol. 2004 Nov;68(11):1417-21.

24. Lopez MA, Liu JH, Hartley BE, Myer CM. Septal hematoma and abscess after nasal trauma. Clin Pediatr (Phila). 2000 Oct;39(10):609-10.

25. Cheng LH, Kang BH. Nasal septal abscess and facial cellulitis caused by community-acquired methicillin-resistant Staphylococcus aureus. J Laryngol Otol. 2010 Sep;124(9):1014-6.

26. Alshaikh N, Lo S. Nasal septal abscess in children: from diagnosis to management and prevention. Int J Pediatr Otorhinolaryngol. 2011 Jun;75(6):737-44

27. Ahmed S, Ashfaq M, Shabbir A. Modified Quilting Sutures: ANew Technique for Hematoma and Abscess of Nasal Septum. J Coll Physicians Surg Pak. 2016 Jun;26(6):531-2

28. Hellmich S. Reconstruction of the destroyed septal infrastructure. Otolaryngol Head Neck Surg. 1989 Feb;100(2):92-4

29. Huizing $E H$. Long term results of reconstruction of the septum in the acute phase of a septal abscess in children. Rhinology. 1984 Mar;22(1):55-63.

30. Fry HJ. The pathology and treatment of haematoma of the nasal septum. Br J Plast Surg. 1969 Oct;22(4):331-5.

31. Thomson CJ, Berkowitz RG. Extradural frontal abscess complicating nasal septal abscess in a child. Int J Pediatr Otorhinolaryngol. 1998 Oct;45(2):183-6.

32. Tan NW, Turvey SE, Byrne AT, Ludemann JP, Kollmann TR. Staphylococcus aureus nasal septal abscess complicated by extradural abscess in an infant. J Otolaryngol Head Neck Surg. 2012 Feb;41(1):E7-12

33. Tien DA, Krakovitz P, Anne S. Nasal septal abscess in association with pediatric acute rhinosinusitis. Int J Pediatr Otorhinolaryngol. 2016 Dec;91:27-9.

34. Cai Y, Saqi A, Haddad J, Jr. Spontaneous Nasal Septal Abscess Presenting as a Soft Tissue Mass in a Child. J Emerg Med. 2017 Apr;52(4):e129-e32.

35. Huang $Y C$, Hung PL, Lin HC. Nasal septal abscess in an immunocompetent child. Pediatr Neonatol. 2012 Jun;53(3):213-5.

36. Alexander AA, Shonka DC, Jr., Payne SC.
Septal hematoma after balloon dilation of the sphenoid. Otolaryngol Head Neck Surg. 2009 Sep;141(3):424-5.

37. Beck AL. Abscess of the nasal septum complicating acute ethmoiditis. Arch Otolaryngol. 1945 Jan;42:275-9.

38. Maeda M, Matsunobu T, Kurioka T, Kurita A, Shiotani A. A case of nasal septal abscess caused by medication related osteonecrosis in breast cancer patient. Auris Nasus Larynx. 2016 Feb;43(1):93-6.

39. Hariri MA, Duncan PW. Infective complications of brief nasotracheal intubation. J Laryngol Otol. 1989 Dec;103(12):1217-8.

40. Cho JG, Lim HW, Zodpe P, Kang HJ, Lee HM. Nasal septal abscess: An unusual presentation of dentigerous cyst. Eur Arch Otorhinolaryngol. 2006 Nov;263(11):104850.

41. da Silva M, Helman J, Eliachar I, Joachims HZ. Nasal septal abscess of dental origin. Arch Otolaryngol. 1982 Jun;108(6):380-1.

42. Pulia MS, Reiff C. Oxycodone insufflation resulting in nasal septal abscess. J Emerg Med. 2014 Jun;46(6):e181-2.

43. Cuddihy PJ, Srinivasan V. An unusual presentation of a nasal septal abscess. J Laryngol Otol. 1998 Aug;1 12(8):775-6.

44. Eavey RD, Malekzakeh M, Wright HT, Jr. Bacterial meningitis secondary to abscess of the nasal septum. Pediatrics. 1977 Jul;60(1):102-4.

45. Soma DB, Homme JH. Multifocal septic arthritis with Group A Streptococcus secondary to nasal septal abscess. Int J Pediatr Otorhinolaryngol. 2011 Jan;75(1):134-6.

\author{
Craig P. Mooney \\ Department of Otolaryngology \\ Head and Neck Surgery \\ Monash Health \\ 867 Centre Rd Bentleigh East Victoria \\ 3165, Australia
}

E-mail:

craig.mooney@monashhealth.org

Tel: +61-43-316 8316 